\title{
Reliability of goniometry to determine the hip range of motion
}

\author{
Bhamare D.S. ${ }^{1}$, Ayare P.P. ${ }^{2}$, Khandge A.V. ${ }^{3}$, Shroff A. S. ${ }^{4}$, Herode P. ${ }^{5}$ \\ ${ }^{1}$ Dr. Dhammapal Sahebrao Bhamare, Associate Professor, Department of Orthopaedics, Dr. D. Y. Patil Medical College, \\ Hospital \& Research Centre, Pune, Maharashtra, India, ${ }^{2}$ Dr. Pinakin Prakash Ayare, Physiotherapist and Kinesiologist at VO2 \\ max Physiotherapy, Rehabilitation and Fitness Academy, Mysore, ${ }^{3}$ Dr. Ashwinkumar Vasant Khandge, Assistant Professor, \\ ${ }^{4}$ Dr. Abhijeet Sudhir Shroff, Associate Professor, Department of Orthopaedics, ${ }^{5}$ Dr. Prafulla Herode, Professor Department of \\ Orthopaedics, above three authors are affiliated with Dr. D. Y. Patil Medical College, Hospital \& Research Centre, Pune, \\ Maharashtra, India.
}

Address for Correspondence: Dr. Ashwinkumar Khandge, Assistant Professor, Department of Orthopaedics, Dr. D Y Patil Medical College and Hospital, Pune, Maharashtra, India. Email: ashwin2087@gmail.com

\begin{abstract}
Purpose: The purpose of this study was to determine the intra-tester and inter-tester reliability of goniometric measurements when measuring the hip joint. Also this study aimed at determining the validity and reliability of goniometry as a tool to diagnose hip pathologies and record the hip range of motion. Materials and Methods: Fifteen recreationally active male participants (age $26.67+4.84$ years) and five physiotherapists took part in this study. Measurement values were got by performing passive range of motion on each participant. Angles derived from the goniometry measurements were compared to the known standard angles of the hip range of motion. An intervention was also performed to see the difference in measurement values after sensitising the physiotherapists to methods of performing goniometry accurately and get precise and valid results. Intraclass coefficient correlations (ICC) were performed to see the correlation between inter-tester and intratester measurements. The Root mean square error (RMSE) was used to determine the accuracy of goniometric values got by physiotherapists after the intervention. The Root mean square error of goniometric measurements of the hip range of motion was calculated in reference to standard values (RMSE- 8-18). Results: The left sided hip internal rotation showed the highest deviation from the standard (RMSE- 16.20). Both sided hip extensions were the least deviated from standards (left- 8.00; right- 8.49). The intraclass coefficient correlations in intra-tester values were persistently higher than 0.70 whereas in the inter-tester setting, the values were less than 0.70. Conclusion: The intra-tester reliability was higher than the inter-tester reliability in our study. We observed that the goniometric measurement values were most reliable for hip extension and least for internal and external rotation, followed by hip abduction and adduction.
\end{abstract}

Keywords: Goniometry, Hip, Pathology, Reliability

\section{Introduction}

Sports is an essential part of many individuals lives; not only athletes performing at competitive levels, but also the common man for the purpose of fitness, leisure and entertainment. Over time, each sport places specific demands on musculoskeletal system, which may result in tissue adaptation or overuse injuries. As a result, many individuals who participate in sports experience injuries that relates to their participation $[1,2,3]$. Hip disorders leading to chronic pain have been significantly noticed in many sports like football, hockey, soccer, rugby, martial arts and tennis $[4,5]$. The pathology may arise either due to congenital malformations of the femur and acetabular rim or excess shear loads on the joints due to the demands

Manuscript Received: $26^{\text {th }}$ June 2017

Reviewed: $6^{\text {th }}$ July 2017

Author Corrected: $14^{\text {th }}$ July 2017

Accepted for Publication: 20 $0^{\text {th }}$ July 2017 of the sport [6,7]. These factors reduce the ability to participate in athletic exercises. The incidence of hip injuries in the athletic population it is 5-6\% [8]. According to National Joint registry, a total of 800,683 primary hip replacements were carried out in England and Wales in 20015/16. Of these, 94 per cent were due to osteoarthritis. Although hip are most commonly related to extra-articular muscular strains or sprains, intra-articular lesions affecting the acetabular labrum, articular cartilage, and capsular and ligamentous structures are frequently the cause of intractable hip pain that may be difficult to diagnose accurately [9]. Studies have proven that clinical techniques like goniometric measurements of the range of movements of the hip in symptomatic adults have helped in the early diagnosis of FAI. Thus, following treatment 
have prevented OA. For hip screening to be utilized on a mass basis, should encompass features like easy availability, affordability, high reliability (both interobserver and intra-observer) and validity. A reliable clinical instrument allows for measurement outcomes that are consistent, accurate, precise and predictable [10]. Over the past recent years, many developments have occurred in measuring ROM; from advanced goniometers to high speed cinematography.

However for clinical purposes, physiotherapists and orthopedicians still rely on goniometry as a tool to quantify baseline limitations of motion, decide on appropriate therapeutic interventions and document the effectiveness of those interventions $[11,12,13,14]$. The universal goniometer remains the most versatile and widely used instrument in practice. [14,15,16]. Many researchers agree that manual goniometry is the most frequent method in physical therapy practice with good to excellent reliability [17]. There are two kinds of reliability. One is intra-tester reliability and other is intratester reliability. Intra-tester reliability refers to whether the device is reliable when testing is administered repeatedly by the same individual. Intertester reliability refers to whether the device is reliable when testing is administered by different individuals. Both types of reliability are important when evaluating a device. Without evidence of reliability, the usefulness of a measurement device is questionable. In rehabilitation science early intervention of hip injury is vital for athlete's career. Goniometry is a popular first method of assessment for musculoskeletal impairments.

An understanding of normal and pathological range of motion using goniometry can help us by providing a differential diagnosis of the underlying hip pathology that helps to determine the need of surgical intervention. Goniometry is a convenient and easy assessment tool which can be readily used by health care professionals to identify acute and chronic injuries in athletes irrespective of availability of a laboratory or clinical set up. This study will focus on determining the reliability of goniometric measurements to be as exclusive indicator of need of surgical intervention. The values obtained using goniometric analysis will be compared with the standard age matched control values. It will also explore intertester and intra-tester reliability of goniometric measurements. The aim of this study is to establish use of goniometry as an intelligent and significant tool to diagnose hip pathology.

\section{Materials and Methods}

This study was done on 15 recreationally active male participants. This study was given ethical clearance by the Ethics committee of the institution after submission of ethical and laboratory risk assessment forms.

Study Design: Cross-Sectional, Observational study.

\section{Inclusion Criteria}

1. 18-40 year old healthy young male.

2. Willingness to participate in the study.

3. Physiotherapists interested in carrying out the assessments.

\section{Exclusion Criteria}

1. Hip pain

2. Past or present hip injury

3. Skin diseases

Participants: The mean age of participants was $26.67 \pm 4.84$ years and the mean height was $173.7 \pm 10.68 \mathrm{cms}$. The mean weight of the participants was $79.41 \pm 12.45 \mathrm{kgs}$ ). All the participants including the physiotherapists were selected by public notice.

Setting: Written consent forms were obtained from all participants before the study began. 15 participants and 5 physiotherapists were selected for inter-tester and intra-tester reliability test of goniometry. The measurements were carried out in the following order: Hip flexion, abduction, adduction, extension, internal rotation and external rotation for the ease of participants. Five long arm goniometers were used in this study. The $360^{\circ}$ goniometers were made of clear transparent plastic with $1^{\circ}$ intervals and the arms measuring 7 inches( Figure 1, Figure 2) The participants were asked to wear only a pair of shorts to facilitate the identification of anatomical surface markings on participants. The treatment couch was arranged so that the participants could lie down on it and physiotherapists could perform the passive ROM and collect data. All the movements for goniometry were done 3 times bilaterally by the physiotherapists. 


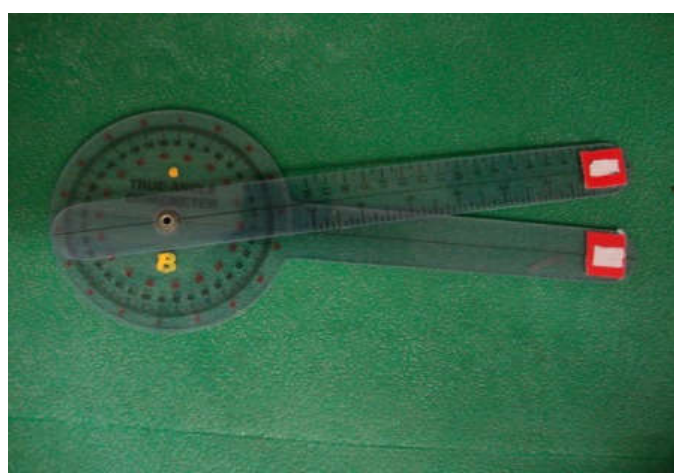

Figure-1: Long arm Universal goniometer

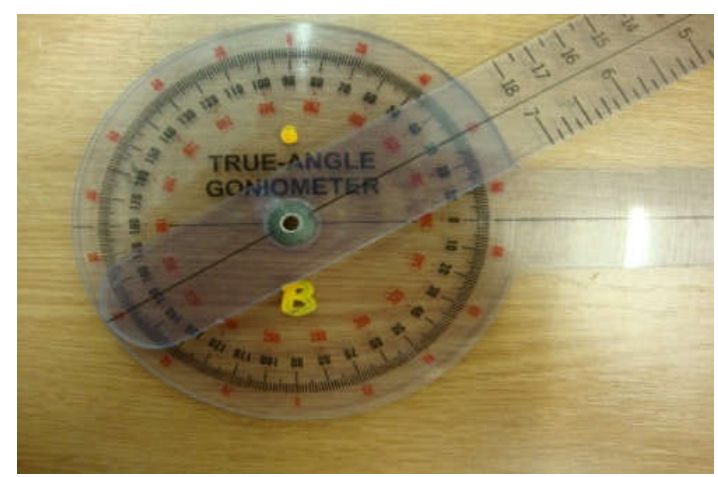

Figure-2: Universal goniometer close up view

Study size: 15

Quantitative Variables: Passive ROM was measured for goniometry.

Statistical Method: The SPSS software was used to perform all statistics in this study (version 11.0). For Intra tester and inter tester reliability, ICC was used. Portney et all suggested that values above 0.75 can be considered good reliability and those below 0.75 poor to moderate reliability [18].

\section{Results}

To determine the reliability of goniometric measurements and deviation from the standard ROM, we compared the goniometric measurements with the standard universally accepted clinical ROM for each hip movement. Table 1 shows RMSE for goniometric measurements in reference with standard values (RMSE 8-18). The left sided internal rotation shows the highest deviation from the standard values (16.20). Hip extension measurements using goniometry are least deviated from standards (left- 8.00; right- 8.49)

Table-1: Validating goniometric ROM measurements against standard clinically accepted ROM measurements for various hip movements.

\begin{tabular}{|c|c|c|}
\hline Hip movement & $\begin{array}{c}\text { Known standard measurements } \\
\text { (in degrees) }\end{array}$ & $\begin{array}{c}\text { Goniometry measurement } \\
\text { ( in degrees) }\end{array}$ \\
\hline Left flexion & 120 & 9.28 \\
\hline Right flexion & 120 & 9.56 \\
\hline Left extension & 30 & 8.00 \\
\hline Right extension & 30 & 8.49 \\
\hline Left abduction & 45 & 11.50 \\
\hline Right abduction & 45 & 10.24 \\
\hline Left adduction & 30 & 9.86 \\
\hline Right adduction & 30 & 9.27 \\
\hline Left internal rotation & 45 & 16.20 \\
\hline Right internal rotation & 45 & 12.76 \\
\hline Left external rotation & 45 & 9.82 \\
\hline Right external rotation & 45 & 12.30 \\
\hline
\end{tabular}

The efficiency of the assessor is an important factor in goniometry. This includes accuracy and precision of measurements taken along with proper techniques of performing goniometry. To determine this, we performed an Intratester reliability test on 2 physiotherapists. ICC was calculated for the measurements made by 2 physiotherapists on 5participants. Also, we tested the inter tester reliability of the physiotherapists performing goniometry. Here, 5 physiotherapists performed goniometry on 5 participants. The reliability is measured according to ICC value on a scale of less reliable $<0.40$, moderately reliable $<0.40-$ 0.70 and highly reliable $>0.70$. According to this scale, Inter tester reliability demonstrated low reliability compared to intra tester (Table 2). Although the intra tester reliability is higher, it varies from person to person, thus efficiency and experience of the physiotherapist is a major contributing factor. 
Original Research Article

Table-2: Determination of inter tester and intra tester reliability in goniometric measurements.

\begin{tabular}{|c|c|c|c|c|}
\hline Intra & Left flexion & Right flexion & Left extension & Right extension \\
\hline Physiotherapist 1 & 0.959 & 0.932 & 0.979 & 0.937 \\
\hline Physiotherapist 2 & 0.858 & 0.900 & 0.843 & 0.897 \\
\hline Inter & & & & .081 \\
\hline $\begin{array}{c}\text { Physiotherapist 1-5 } \\
\text { ICC }\end{array}$ & 0.480 & .384 & 0.188 & 0.307 \\
\hline $\begin{array}{c}\text { Cronbach's alpha } \\
\text { Intra }\end{array}$ & Left abduction & Right abduction & Left adduction & Right adduction \\
\hline Physiotherapist 1 & 0.848 & 0.691 & 0.982 & 0.907 \\
\hline Physiotherapist 2 & 0.839 & 0.831 & 0.759 & 0.645 \\
\hline Inter & & & & 0.586 \\
\hline Physiotherapist 1-5 & 0.349 & .896 & -0.63 & .211 \\
\hline ICC & & & & 0.572 \\
\hline Cronbach's alpha & 0.728 & 0.632 & -.012 & Right external \\
\hline Intra & Left internal & Right internal & Left external & rotation \\
\hline rotation & rotation & 0.940 & 0.935 \\
\hline Physiotherapist 1 & 0.893 & 0.965 & 0.852 & 0.841 \\
\hline Inter & 0.648 & 0.744 & & -0.001 \\
\hline
\end{tabular}

The table shows inter tester and intra tester ICC values for various hip movements. Intratester reliability is measured as ICC of measurements taken by each physiotherapist on five participants. Inter tester reliability is measured as ICC of measurements taken by five physiotherapist on five participants.

\section{Discussion}

The goal of any clinical method of assessment is to produce accurate and reliable results [19]. This would ensure that measurements taken with a particular instrument would reflect true changes within the patient, rather than measurement error. If the measurement device is not accurate and reliable, it is not possible be confident in the results of repeated measures.

Apart from pain, reduction in functional range of motion is a symptom of underlying hip pathology. As severity of the pathology increases, the ROM of hip becomes more restricted and affects not only in athletic activities, but also affects activities of daily living. Measurement of hip function is important to detect any underlying hip pathology or assessing the outcomes of surgery and therapy. Goniometer proves to be a widely used tool of assessment by clinicians to assess ROM.

It has the advantage of being easy to use and inexpensive. Goniometric readings have been reliable and accurate, but it depends on the assessor's previous experience. The participants were assessed by physiotherapists using universal goniometers. Measurement protocol (position of participant) was kept same for all the physiotherapists.

This may be since the ROM may be vastly varied amongst the participants. Also, while performing measurements, researchers and physiotherapists have neglected the effect of stabilization of pelvis, thus allowing compensatory movement to occur and increase in range of motion. This is one of the reasons why many clinicians prefer prone lying with knee bend technique to prevent hip movements while measuring hip rotations. Much variability is also seen in hip flexion.

During hip flexion, the pelvis needs to be stabilized. If the pelvis is not stabilized, additional ROM is acquired by Lumbo-pelvic rhythm. The lumbo -pelvic rhythm is a compensatory mechanism which occurs in hip flexion and abduction in both lumbar spine and pelvis, where the segment moves or tilts to produce a concomitant movement. In the intra tester and inter tester reliability, the goniometer has proven as a tool of precision. This study shows a higher Intra tester reliability than inter 
tester reliability. This result is in agreement with results performed to assess inter tester and intra tester reliability of goniometry [20,21]. Though the intra tester reliability is greater than inter tester, it depends upon the expertise of the assessor.

Limitations- One limitation was the number of participants available for the study. It was difficult to gather more number of participants, since the time of study coincided with yearly vacations. Also, researchers failed to apply proper technique of performing movements on participants. For example, the hip was not completely stabilized during hip flexion, so values more than normal were recorded.

\section{Conclusion}

The present study has presented results from goniometric measurement of the hip ROM. The values from the study were most reliable for hip extension and least for internal and external rotation, followed by hip abduction and adduction. Intra tester reliably was seen higher than inter tester reliability in our study. The present study adds to our knowledge that a simple test like goniometry is accurate and reliable in detecting changes in the hip ROM. If this is considered, then goniometry can certainly be used as a valid measure to detect underlying pathology in hip and the surgical intervention can be done on basis of it.

\section{Contribution of Authors}

Bhamare DS: Conceptualisation and study design Ayare PP: Conceptualisation and study design Khandge AV: Materials and methods and discussion Shroff AS : Statistics and discussion

Herode P: Statistics and discusiion

Conflict of interest: None declared. Funding: Nil, Permission from IRB: Yes

\section{References}

1. Klenerman L. ABC of sports medicine. Musculoskeletal injuries in child athletes. BMJ. 1994 Jun $11 ; 308(6943): 1556-9$.

2. Gore RM, Rogers LF, Bowerman J, Suker J, Compere CL. Osseous manifestations of elbow stress associated with sports activities.American Journal of Roentgenology. 1980 May 1;134(5):971-7.

3. Kaufman KR, Brodine SK, Shaffer RA, Johnson CW, Cullison TR. The effect of foot structure and range of motion on musculoskeletal overuse injuries. Am J Sports Med. 1999 Sep-Oct;27(5):585-93.
4. Philippon M, Schenker M, Briggs K, Kuppersmith D. Femoroacetabular impingement in 45 professional athletes: associated pathologies and return to sport following arthroscopic decompression. Knee Surgery, SportsTraumatology,Arthroscopy.2007Jul 1;15(7):908-14.

5. Shindle MK, Voos JE, Heyworth BE, Mintz DN, Moya LE, Buly RL, Kelly BT. Hip arthroscopy in the athletic patient: current techniques and spectrum of disease. JBJS. 2007 Oct 1;89(suppl_3):29-43.

6. Jaberi FM, Parvizi J. Hip pain in young adults: femoroacetabular impingement. The Journal of arthroplasty. 2007 Oct 31;22(7):37-42.

7. Brian P, Bernard S, Flemming D. Femoroacetabular impingement: screening and definitive imaging. Semin Roentgenol. 2010 Oct; 45(4):228-37. doi: 10.1053/j.ro. 2009.12.006.

8. Keogh MJ, Batt ME. A review of femoroacetabular impingement in athletes. Sports Med.2008;38(10):863-78.

9. Burnett RS, Della Rocca GJ, Prather H, Curry M, Maloney WJ, Clohisy JC. Clinical presentation of patients with tears of the acetabular labrum. J Bone Joint Surg Am. 2006 Jul;88(7):1448-57.

10. Bear-Lehman J, Abreu BC. Evaluating the hand: issues in reliability and validity. Phys Ther. 1989 Dec;69 (12): 1025-33.

11. Sabari JS, Maltzev I, Lubarsky D, Liszkay E, Homel P. Goniometric assessment of shoulder range of motion: comparison of testing in supine and sitting positions. Arch Phys Med Rehabil. 1998 Jun;79(6):647-51.

12. Kilgour GM, Stott S, McNair P. Lower limb sagittal range of motion: reliability of measures and normative values. New Zealand Journal of Physiotherapy. 2002;30 (2):8-25.

13. Harris SR, Smith LH, Krukowski L. Goniometric reliability for a child with spastic quadriplegia. Journal of pediatric orthopedics. 1984 Dec;5(3):348-51.

14. Gajdosik RL, Bohannon RW. Clinical measurement of range of motion. Review of goniometry emphasizing reliability and validity. Phys Ther. 1987 Dec;67(12): 1867-72.

15. Clapper MP, Wolf SL. Comparison of the reliability of the Orthoranger and the standard goniometer for assessing active lower extremity range of motion. Phys Ther. 1988 Feb;68(2):214-8. 


\section{Original Research Article}

16. Fish DR, Wingate L. Sources of goniometric error at the elbow. Phys Ther. 1985 Nov;65(11):1666-70.

17. Riddle DL, Rothstein JM, Lamb RL. Goniometric reliability in a clinical setting. Shoulder measurements. Phys Ther. 1987 May;67(5):668-73.

18. Portney LG, Watkins MP. Validity of measurements. Foundations of clinical research: Applications to practice. $2000 ; 2$.

19. Bartlett MD. HIP FLEXION CONTRACTURES: A COMPARISON OF MEASUREMENT METHODS. Journal of Pediatric Orthopaedics. 1986 Jan 1;6(1):117.
20. Holla JF, van der Leeden M, Roorda LD, BiermaZeinstra SM, Damen J, Dekker J, Steultjens MP. Diagnostic accuracy of range of motion measurements in early symptomatic hip and/or knee osteoarthritis. Arthritis Care Res (Hoboken). 2012 Jan;64(1):59-65. doi: 10.1002/ acr.20645.

21. T'Jonck L, Schacke S, Lysens R, Witvrouw E, Delvaux K, Peers K. Intertester and intratester reliability of the standard goniometer and the cybex edi 320 for active and passive shoulder range of motion in normals and patients. InProceedings of the First Conference of the ISG 1997 (pp. 41-47).

\section{How to cite this article?}

Bhamare D.S, Ayare P.P, Khandge A.V, Shroff A. S, Herode P. Reliability of goniometry to determine the hip range of motion. Int J surg Orthopedics.2017;3(3):66-71.doi:10.17511/ijoso.2017.i03.03. 